\title{
INVESTIGATION OF SUBJECTIVE AND OBJECTIVE THERMAL COMFORT IN THE CASE OF CEILING AND WALL COOLING SYSTEMS
}

\author{
G. L. SZABÓ ${ }^{\mathrm{a}}, F . K A L M A ́ R^{\mathrm{b}}$ \\ Department of Building Services and Building Engineering, University of Debrecen, 4028 Debrecen, Ótemető u. 2-4, Hungary \\ aE-mail: 1.szabo.gabor@eng.unideb.hu \\ ${ }^{\mathrm{b}}$ Corresponding author; E-mail: fkalmar@eng.unideb.hu
}

Energy saving in buildings is one of the most important research directions in the building sector. Energy saving solutions should not lead to decreased indoor environment quality. Because of the increased number of summer heat waves, cooling systems are widely used to assure thermal comfort in buildings. In this paper, ceiling cooling and wall cooling systems were tested and compared from the thermal comfort point of view using 24 subjects (12 women and 12 men). The cooling ceiling and wall surface and the supply/return temperatures were similar. Analysing the obtained subjective answers, no significant differences were obtained on average or by gender. However, significant differences were obtained between the subjective answers and the calculated PMV values. Furthermore, the occupant's reaction was different after switching off the ventilation and cooling systems.

Keywords: ceiling cooling, intermittent operation, predictive mean vote, thermal comfort, wall cooling

\section{Introduction}

In recent years, energy savings in buildings has become one of the most important issues in the building sector. During the design and construction process, the health and well-being of occupants must be the primary goal of architects and building contractors. The available technologies allow the construction of nearly zero or net zero energy buildings with a high comfort level. However, large glazed areas can lead to a high heat load during summer periods if shading elements are not built in or used properly. Unfortunately, the European climate change demonstrated by Luterbacher et al. [1] especially in the summer period, has negative effects both on the energy saving efforts and on the indoor thermal comfort in buildings. According to Schär et al. the European summer climate might experience a pronounced increase in yearto-year variability in response to greenhouse-gas forcing [2]. The European continent was affected by extremely hot heat waves in the summer of 2003. Fischer et al. looked for soil moisture-atmospheric interactions and found that soil moisture perturbations can affect continental-scale circulation and that there is a positive feedback between the two [3]. The results of Zampieri et al. showed that a difference in the initial soil moisture over southern Europe increased the anticyclonic conditions and atmospheric stability, inhibiting wet convection and favouring the establishment of stagnant weather [4]. Analysis of a long-term temperature series at Prague-Klementinum revealed that the July 2006 heat wave, covering 33 consecutive days, was the longest and most severe individual heat waves since 1775 [5]. Founda and Giannakopoulos analysed the hot summer of 2007 in Athens, and they found that Greece experienced the warmest summer of its history, with record breaking temperatures observed at a number of stations [6]. The heat wave in 2010 led to record warmth at many locations in Central and Eastern Europe. Finland experienced a stretch of record warmth in July. Most of western Russia experienced the hottest summer in recorded history [7]. According

This is an open-access article distributed under the terms of the Creative Commons Attribution-NonCommercial 4.0 International License (https://creativecommons.org/licenses/by-nc/4.0/), which permits unrestricted use, distribution, and reproduction in any medium for non-commercial purposes, provided the original author and source are credited, a link to the CC License is provided, and changes - if any - are indicated. 
to Barriopedro et al. "mega-heatwaves", such as the 2003 and 2010 events, likely broke the 500-year-long seasonal temperature records over approximately $50 \%$ of Europe [8]. The effects of extremely hot summer heat waves had serious socio-economic consequences and affected outdoor thermal comfort [9-11]. In such weather conditions, the appropriate indoor conditions in buildings can only be assured by cooling systems. However, cooling contributes significantly to the energy use of buildings. Stetiu investigated the energy use of radiant cooling and all-air cooling systems and drew the conclusion that the simulated radiant cooling system requires less energy and peak power to condition the base-case space than the simulated all-air system [12]. The energy performance of the cooling ceiling was simulated and analysed by Imanari et al., and they proved that by using a radiant ceiling panel system in one of the three floors of the simulated building, energy consumption could be reduced by $10 \%$ [13]. Consequently, radiant cooling might be advantageous from an energy point of view. Several authors investigated the thermal comfort of occupants in closed spaces equipped with cooling ceiling systems [14-18]. Most of these studies found that radiant systems can be very effective cooling terminal units, utilising fairly high temperature cooling media and thus increasing the efficiency of the cooling plant's equipment. At the same time, Oxizidis and Papadopoulos found that the limited capacity of radiant cooling panels, together with their inability to handle latent cooling loads, does not allow them to ensure satisfactory thermal comfort conditions, at least according to deterministic comfort evaluation standards [18]. Heat exchange by radiation plays an important role for human subjects in subjective thermal evaluation of the environment. Consequently, cold surfaces can contribute efficiently to the subjective thermal comfort improvement in buildings during hot summer days. In this paper, a thermal comfort analysis was performed using ceiling cooling and wall cooling in a test room. The subjective answers related to thermal comfort were compared with the objective PMV values calculated based on the measured temperature, humidity and air velocity values in the test room.

\section{Materials and methods}

At the Department of Building Services and Building Engineering, University of Debrecen in the laboratory of Indoor Environment Quality, a test room was built to evaluate the thermal comfort of occupants under various comfort parameters. The test room is placed in a climatic ("adiabatic") chamber built from $15 \mathrm{~cm}$ thick PUR panels. In the space left between the walls and ceilings of the two rooms, the air temperature can be set between $-15{ }^{\circ} \mathrm{C}$ and $+34{ }^{\circ} \mathrm{C}$. The internal dimensions of the test room are: $2.49 \times 3.65 \times 2.56 \mathrm{~m}$ (Fig. 1). The $20 \mathrm{~cm}$ thick test room walls are built from brick with vertical holes. In the floor, ceiling and one wall of the test room, hydraulic circuits are placed to permit surface heating or cooling of the room. Fresh air can be introduced into the room either by mixing or

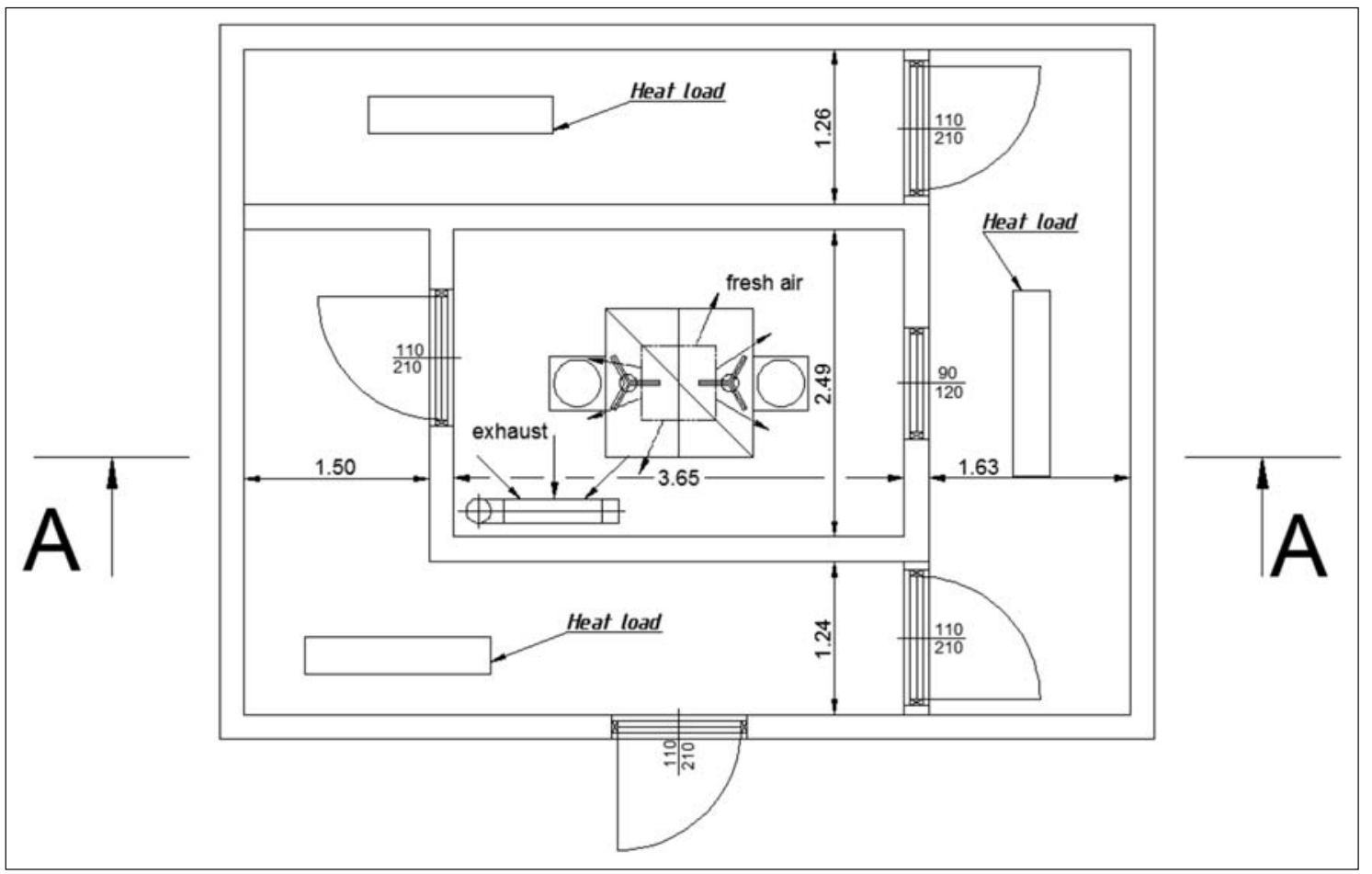

Fig. 1. Setting up the measurements in the IEQ laboratory 


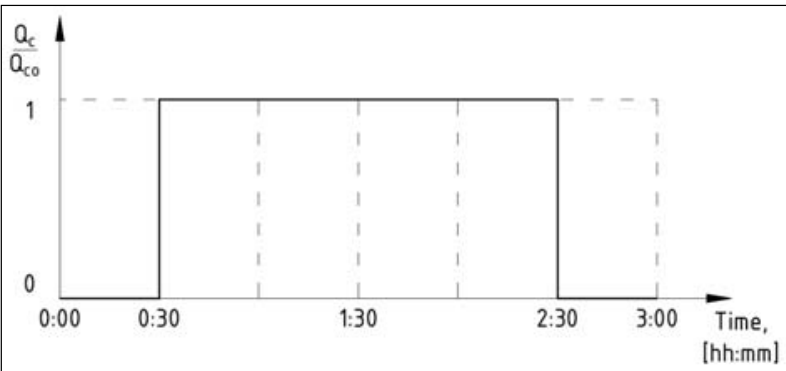

Fig. 2. Operation schedule of the cooling systems

displacement ventilation. We chose the balanced mixing ventilation mode. Fresh air was supplied under the ceiling above the occupants. The exhaust air terminal device was placed above the floor.

The main purpose of our research was to compare the thermal comfort obtained in the test room in the case of high heat loads using ceiling or wall cooling. The heat load was chosen to obtain, without cooling, a mean radiant temperature and air temperature of $29{ }^{\circ} \mathrm{C}$. The area of the cooling surface was $7.0 \mathrm{~m}^{2}$, both for the ceiling and wall cooling systems. The duration of the measurements was 3.0 hours. For the first 30 minutes, subjects sat in the test room, and the ventilation and the cooling systems were switched off. After the first half hour, both the ventilation and the cooling system were switched on and kept in operation for two hours. In the test room, two subjects were sitting and solving specific tests simultaneously. Fresh air flow was fixed at $100 \mathrm{~m}^{3} / \mathrm{h}\left(50 \mathrm{~m}^{3} / \mathrm{h} /\right.$ person $)$, and the temperature was controlled at $29{ }^{\circ} \mathrm{C}$. During the last 30 minutes, both the ventilation and cooling systems were switched off (Fig. 2).

The role of the first 30 minutes was acclimatization to these relative high indoor temperatures. In the last 30 minutes, the thermal comfort was analysed, assuming intermittent operation of the cooling system. The measurements were performed with 24 subjects (12 men and 12 women), the clothing was $0.5 \mathrm{clo}$, the
Table 1. Age, height and weight of subjects

\begin{tabular}{lccc}
\hline Subjects & Age [years] & Height $[\mathrm{cm}]$ & Weight $[\mathrm{kg}]$ \\
\hline Women & $22-26$ & $153-170$ & $48-66$ \\
Men & $22-26$ & $170-190$ & $73-98$ \\
\hline
\end{tabular}

activity level was 1.0 met. Subjects were not allowed to change clothes during measurements. The main parameters of the subjects involved in the measurements are presented in Table 1.

In the test room, the expected starting value of $29^{\circ} \mathrm{C}$ for the air and mean radiant temperatures were obtained using a heat load of $6.0 \mathrm{~kW}$ in the space between the test room walls and the adiabatic chamber (Fig. 1). The heat load was operating continuously during the measurements.

During the experiments, the air temperature, the mean radiant temperature, the air velocity, the relative humidity and the $\mathrm{CO}_{2}$ concentration were measured at $1.1 \mathrm{~m}$ height. The measurements of the comfort parameters were performed with TESTO 435 and TESTO 480 instruments using an air temperature probe (accuracy: $\pm\left(0.3{ }^{\circ} \mathrm{C}+0.1 \%\right.$ of the measured value) $)$, globe temperature probe (accuracy: $\pm\left(0.3{ }^{\circ} \mathrm{C}\right.$ $+0.1 \%$ of the measured value) $), \mathrm{CO}_{2}$ probe (accuracy: $\pm\left(75 \mathrm{ppm} \mathrm{CO}_{2}+3 \%\right.$ of the measured value $\left.)\right)$, relative humidity probe (accuracy: $\pm 2 \% \mathrm{RH}$ ) and air velocity probe (accuracy: $\pm(0.03 \mathrm{~m} / \mathrm{s} \pm 5 \%$ of the measured value)). Two instruments and two probes of each type were fixed in the test room, according to Fig. 1. Small differences between the measured values were registered: $0.2 \mathrm{~K}$ for temperatures, $12 \mathrm{ppm}$ for $\mathrm{CO}_{2}, 2 \%$ for relative humidity, and $0.02 \mathrm{~m} / \mathrm{s}$ for air velocity. In the calculation of the predicted mean vote, the measured values of these parameters were taken into account for each subject.

During measurements, subjects filled out a short questionnaire every 15 minutes. We asked subjects to give answers to the following questions:

1. On the 7-point thermal comfort scale, mark your thermal comfort sensation

2. Is the air velocity acceptable? If not, how should it be changed?

3. Do you feel a draught?

If yes, please specify where you feel the draught head neck arms back

4. Are you content with the indoor air quality?

5. Are you contend with the surface temperatures? If not, how should it be changed?

floor temperature: ceiling temperature: internal walls temperature: external walls temperature: yes

increase yes

no decrease no

\begin{tabular}{|c|c|}
\hline legs & ankles \\
\hline yes & no \\
\hline yes & no \\
\hline
\end{tabular}

increase

decrease

increase

decrease

increase decrease

increase decrease 


\section{Results}

The air temperature variation at $1.1 \mathrm{~m}$ during the 3.0 hour measurement can be seen in Fig. 3 for the wall and ceiling cooling modes. Because of the hysteresis of the control system and the thermal inertia of the heating and cooling systems, the air temperature has small variations between different measurements, but the maximum values of these deviations were $\pm 0.5^{\circ} \mathrm{C}$.

The mean radiant temperature variation can be seen in Fig. 4. The variation of the mean radiant temperature between different measurements was \pm 0.3 ${ }^{\circ} \mathrm{C}$. These deviations were lower than the deviations of the air temperature. The thermal inertia of the building elements helps to maintain the mean radiant temperature at the desired value.
The variation of the relative humidity in the test room (measured at $1.1 \mathrm{~m}$ height) is shown in Fig. 5.

The $\mathrm{CO}_{2}$ concentration of the indoor air is presented in Fig. 6.

The $\mathrm{CO}_{2}$ and relative humidity diagrams show the operation mode of the ventilation system.

The air velocity variation during measurements (measured at $1.1 \mathrm{~m}$ height) can be seen in Fig. 7 .

The air velocity values in the occupants' zone were low and similar in the case of wall and ceiling heating; consequently, the microenvironment was suitable for testing the effects of radiant cooling systems on subjective thermal comfort.

Using the above presented microclimate parameters, the PMV can be calculated with the equation [19]:

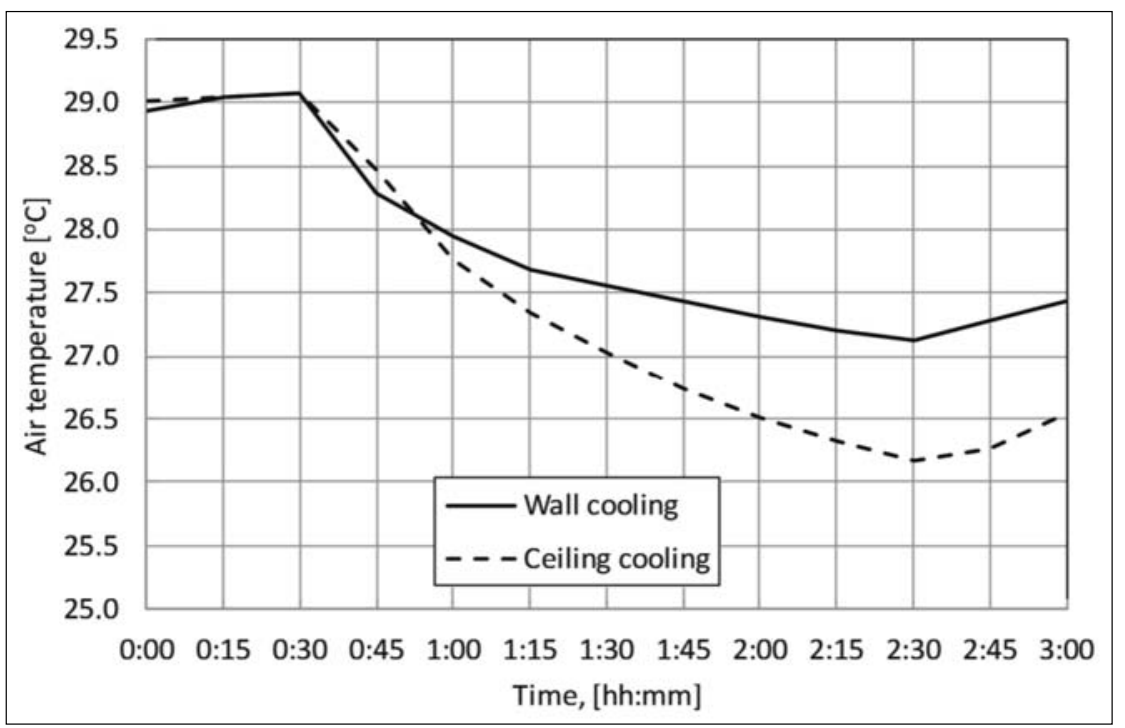

Fig. 3. Air temperature variation during the measurements

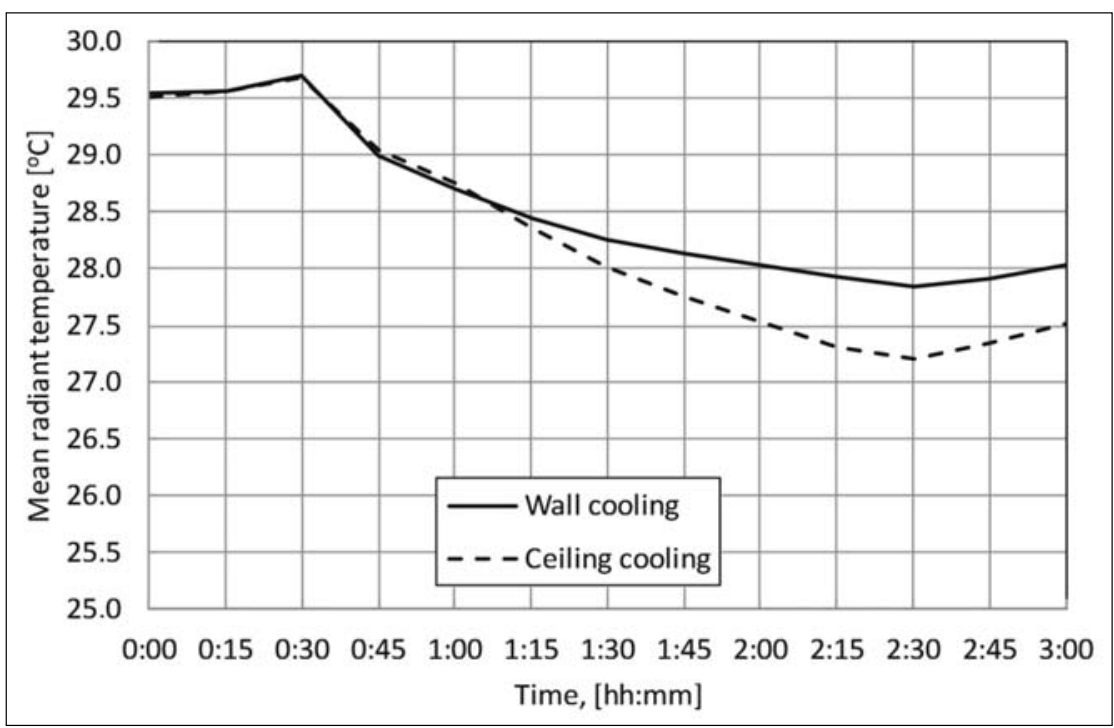

Fig. 4. Mean radiant temperature variation during the measurements 


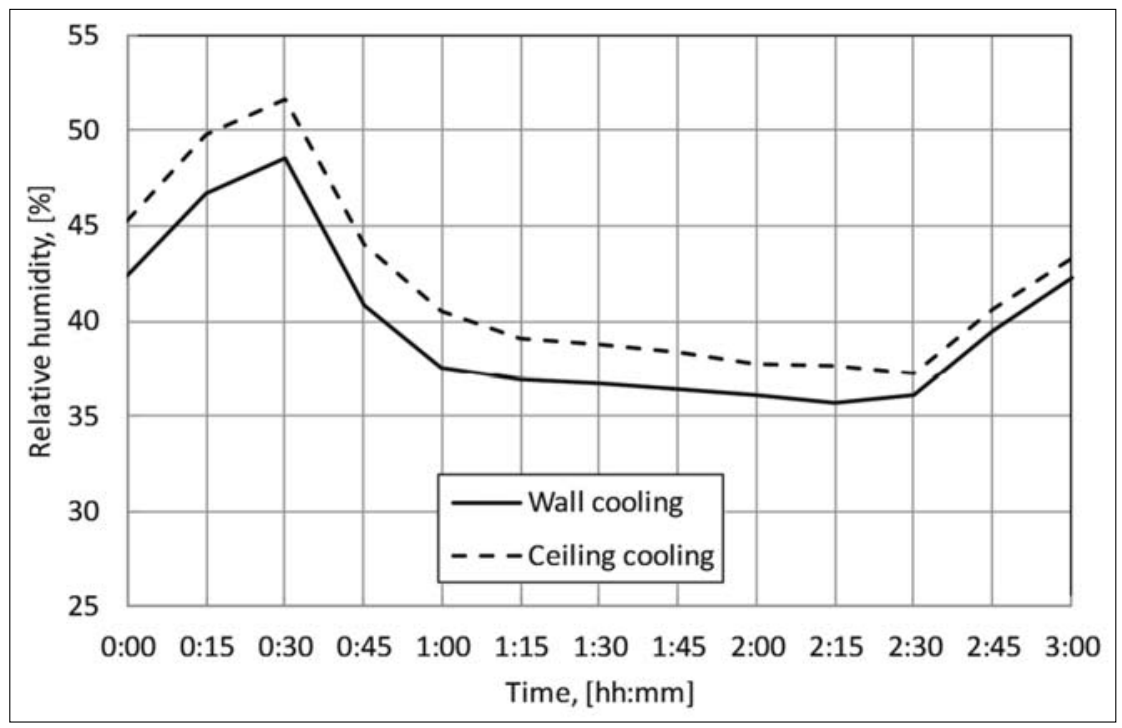

Fig. 5. Relative humidity in the test room

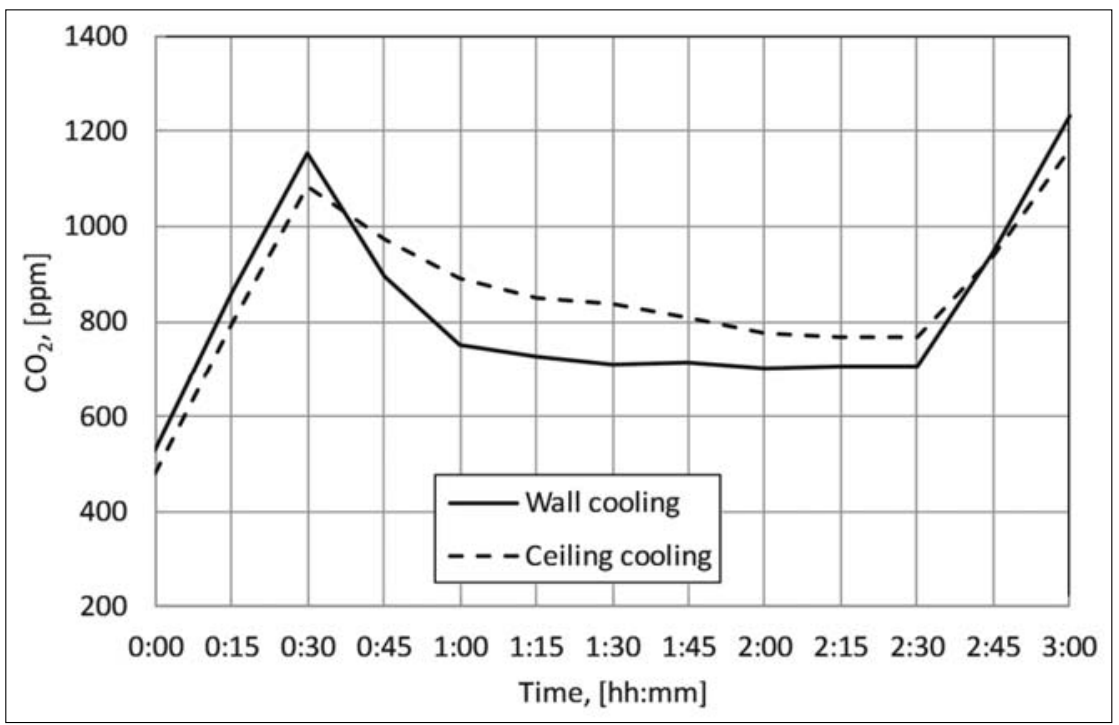

Fig. 6. $\mathrm{CO}_{2}$ concentration in the air

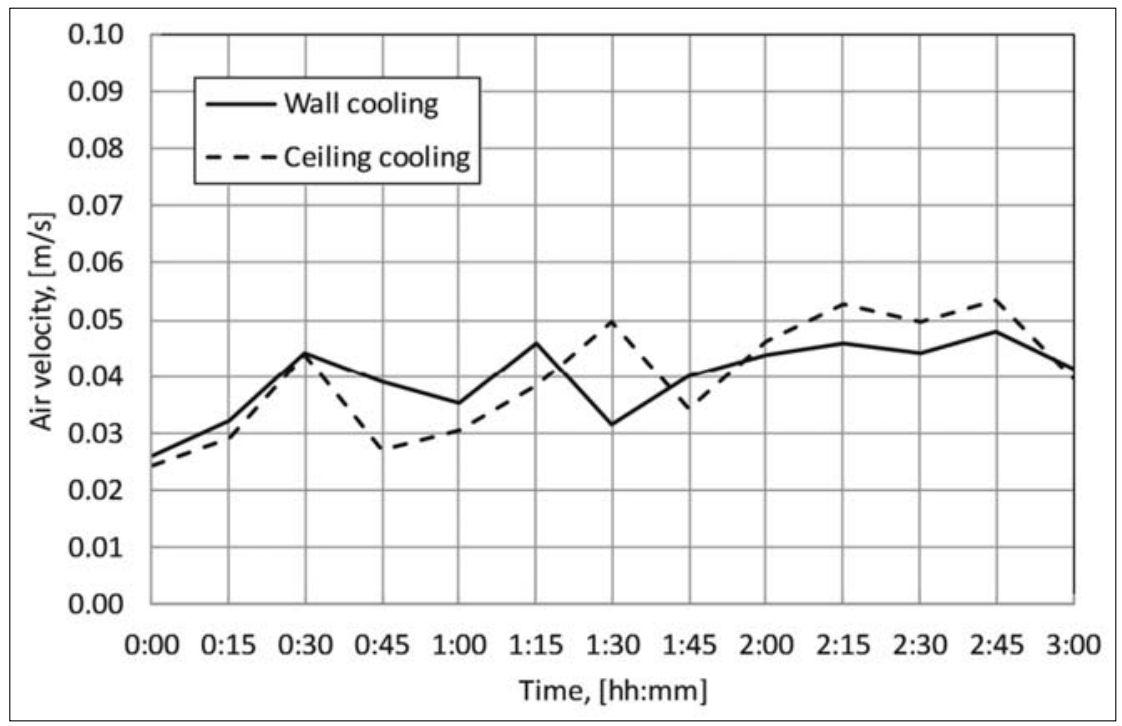

Fig. 7. Air velocity at $1.1 \mathrm{~m}$ height 
$P M V=(0.303 \exp -0.036 M+0.028)$

$\times\left\{(M-W)-3.05 \cdot 10^{-3}\left[5733-6.99\left(M-W-p_{a}\right]\right.\right.$

$-0.42[(M-W)-58.15]-1.7 \cdot 10^{-5} M\left(5867-p_{a}\right)$

$-0.0014 M\left(34-t_{a}\right)-3.96 \cdot 10^{-8} f_{c l}\left[\left(t_{c l}+273\right)^{4}\right.$

$\left.-\left(\overline{t_{r}}+273\right)^{4}\right]-f_{c l} h_{c}\left[\left(t_{c l}-t_{a}\right)\right\}$,

where $t_{a}$ is the indoor air temperature, $\left[{ }^{\circ} \mathrm{C}\right] ; p_{a}$ is the water vapour partial pressure, in $[\mathrm{Pa}]$; and $I_{c l}$ is the thermal resistance of clothing $\left[\mathrm{m}^{2} \mathrm{~K} / \mathrm{W}\right]$.

The clothing surface temperature can be determined using Eq. (2) [20].

$$
\begin{aligned}
t_{c l} & =35.7-0.028(M-W) \\
& -I_{c l}\left\{h _ { r } f _ { c l } 1 0 ^ { - 8 } \left[\left(t_{c l}+273\right)^{4}\right.\right. \\
& \left.-\left(\bar{t}_{r}+273\right)^{4}\right]+f_{c l} h_{c}\left(t_{c l}-t_{a}\right),
\end{aligned}
$$

where $M$ is the metabolic rate $\left[\mathrm{W} / \mathrm{m}^{2}\right]$ of the body surface area; and $W$ is the external work $\left[\mathrm{W} / \mathrm{m}^{2}\right]$, which is equal to zero for most activities.

The radiative heat transfer coefficient $h_{r}$ is given by Eq. (3) [20]:

$$
h_{r}=5,67 \cdot 10^{-8} \varepsilon \frac{A_{r}}{A_{D}} \frac{\left(t_{c l}+273\right)^{4}-\left(\overline{t_{r}}+273\right)^{4}}{\left(t_{c l}-\overline{t_{r}}\right)} \text {, }
$$

where the ratio of the body's $4 \pi$ radiation area, $A_{r}$ to $A_{D}$, is 0.67 for a crouching subject, 0.7 for sitting and 0.73 for the standing position; and $\varepsilon$ is emittance of the clothed human body.

The clothing area factor can be determined using Eq. (4) [19]:

$$
f_{c l}=\left\{\begin{array}{l}
1.00+1.290 I_{c l} \text { for } I_{c l}<0.078 \mathrm{~m}^{2} \mathrm{~K} / \mathrm{W} \\
1.05+0.645 I_{c l} \text { for } I_{c l}>0.078 \mathrm{~m}^{2} \mathrm{~K} / \mathrm{W}
\end{array}\right.
$$

The convective heat transfer coefficient $h_{c}$ can be determined using equation (5) [19]:

$$
h_{c}= \begin{cases}X & \text { for } X>Y, \\ Y & \text { for } X<Y,\end{cases}
$$

where $X=2.38\left[t_{c l}-t_{a}\right]^{1 / 4}, Y=12.1\left[v_{a r}\right]^{1 / 2}$ and $v_{a r}$ is the relative air velocity (relative to the human body), in $\mathrm{m} / \mathrm{s}$.

The mean radiant temperature is given by Eq. (6) [19]:

$$
\bar{t}_{r}=\left[\sum_{i=1}^{n} F_{P-A_{i}} T_{s i}^{4}\right]^{1 / 4}-273,
$$

where $F_{P-A_{i}}$ are the angle factors between the human body and surface $i$.

The obtained PMV values are shown in Fig. 8. At a certain moment of the measurement process, the small variations of the calculated PMV values are caused by the small variations of the microclimate parameters. Fig. 9.

The subjective thermal comfort is presented in

\section{Discussion}

When the measurements were started, the air temperature and the mean radiant temperature were set at 29 and $29.5^{\circ} \mathrm{C}$, respectively, in the test room. After performing 12 measurements for the ceiling cooling system and 12 measurements for the wall cooling system, because of the hysteresis of the control system and the thermal inertia of hydraulic system, small differences between the microclimate parameters were registered. During the first 30 minutes, because of the heat released by the occupants, the heat load in the test room increased. The air and mean radiant temperatures also increased. The heat delivered by occupants

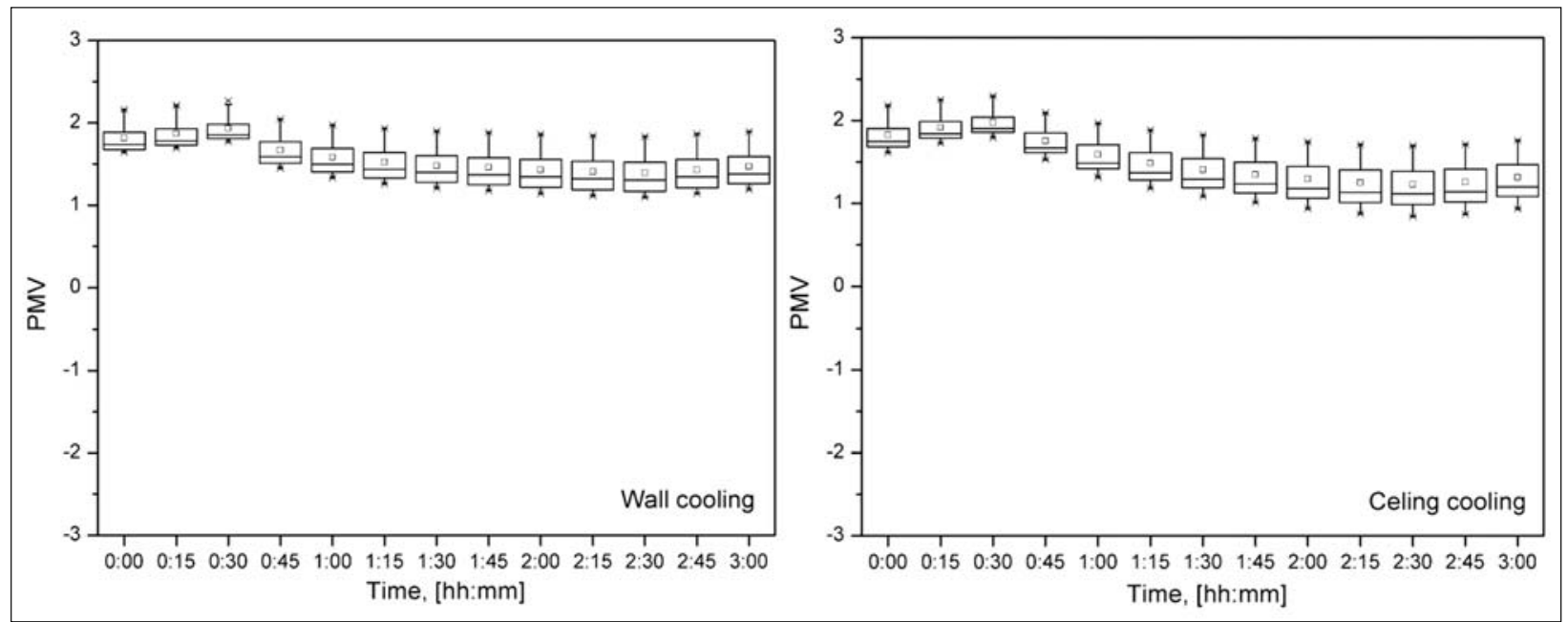

Fig. 8. Predicted mean votes for ceiling and wall cooling 


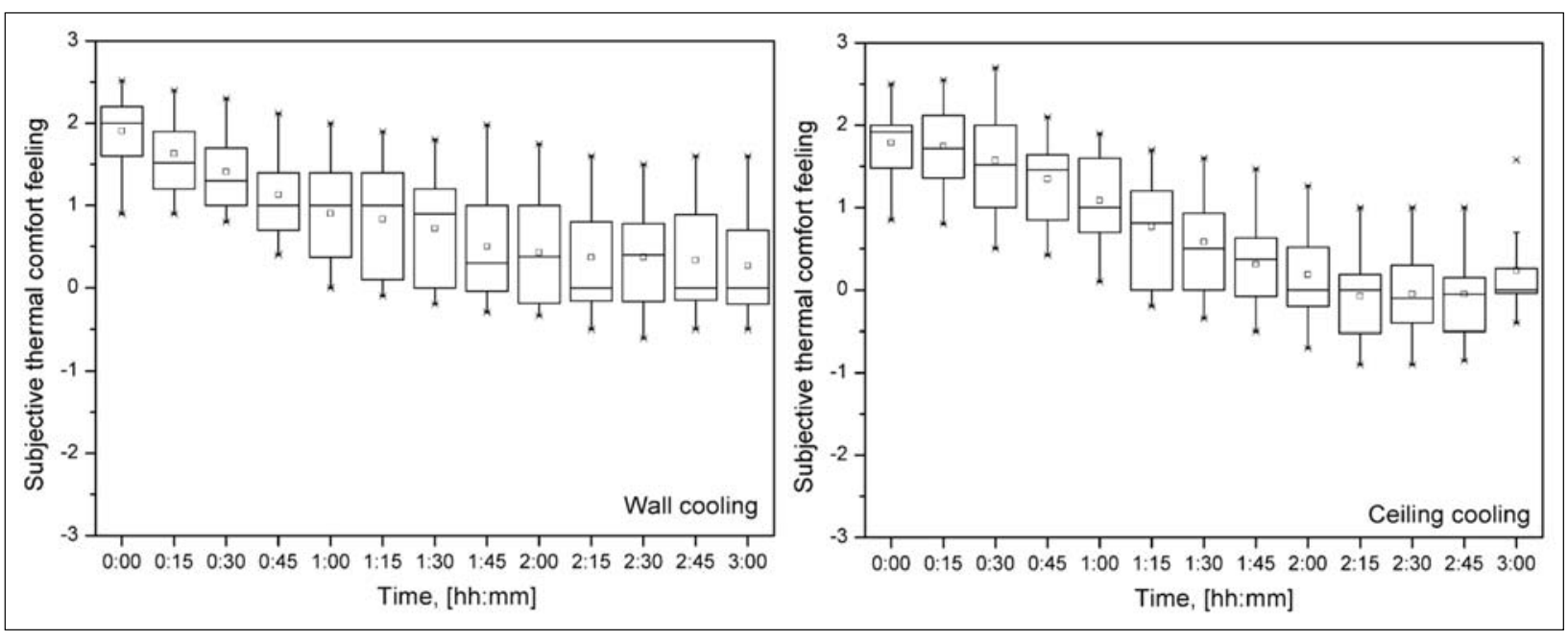

Fig. 9. Subjective thermal comfort of occupants

was different because their body parameters were diverse. As a consequence, the temperatures and relative humidity in the test room had small differences in the case of different groups. The relative humidity of the air at the beginning was approximately $45 \%$ and was kept between $35 \%$ and $52 \%$ during measurements. Because neither the ventilation nor the cooling systems were in operation during the first and last 30 minutes of the measurements, the relative humidity and the $\mathrm{CO}_{2}$ concentration in the air increased significantly during these periods. The $\mathrm{CO}_{2}$ concentra- tion practically doubled in 30 minutes. Based on the measured values, the calculated PMV was +1.8 and decreased at a very small rate during the three hours of measurements. The subjective thermal comfort of occupants started at +2.0 and decreased slightly in the first 30 minutes, even though the air and mean radiant temperatures increased in this period of time. This decrease of thermal comfort can be caused by acclimatization. After starting the cooling systems, the subjective thermal comfort decreased to almost 0 within two hours (even negative values were registered). The an-

Table 2. Significance analysis between the calculated PMV and the subjective thermal comfort of occupants (wall cooling, men)

\begin{tabular}{lccccccl}
\hline & Mean Diff & SEM & Alpha & Sig & LCL & UCL & \multicolumn{1}{c}{ Overall ANOVA } \\
\hline $0: 00$ & 0.201 & 0.179 & 0.05 & 0 & -0.170 & 0.571 & No significant difference \\
$0: 15$ & 0.538 & 0.199 & 0.05 & 1 & 0.126 & 0.951 & Significant difference \\
$0: 30$ & 0.739 & 0.258 & 0.05 & 1 & 0.205 & 1.273 & Significant difference \\
$0: 45$ & 0.813 & 0.244 & 0.05 & 1 & 0.307 & 1.319 & Significant difference \\
$1: 00$ & 0.988 & 0.306 & 0.05 & 1 & 0.353 & 1.623 & Significant difference \\
$1: 15$ & 1.035 & 0.298 & 0.05 & 1 & 0.416 & 1.653 & Significant difference \\
$1: 30$ & 1.114 & 0.284 & 0.05 & 1 & 0.524 & 1.703 & Significant difference \\
$1: 45$ & 1.428 & 0.302 & 0.05 & 1 & 0.801 & 2.055 & Significant difference \\
$2: 00$ & 1.451 & 0.295 & 0.05 & 1 & 0.840 & 2.062 & Significant difference \\
$2: 15$ & 1.486 & 0.285 & 0.05 & 1 & 0.895 & 2.077 & Significant difference \\
$2: 30$ & 1.403 & 0.278 & 0.05 & 1 & 0.827 & 1.979 & Significant difference \\
$2: 45$ & 1.431 & 0.295 & 0.05 & 1 & 0.820 & 2.043 & Significant difference \\
$3: 00$ & 1.449 & 0.296 & 0.05 & 1 & 0.836 & 2.063 & Significant difference \\
\hline
\end{tabular}

Mean Diff - difference between means

SEM - standard error of means

Alpha - significance level

$\mathrm{Sig}-\mathrm{Sig}$ equal to 0 indicates that the mean difference is not significant at the 0.05 level

Sig equal to 1 indicates that the mean difference is significant at the 0.05 level

LCL - lower confidence limit

$\mathrm{UCL}$ - upper confidence limit 
swers related to subjective thermal comfort were analysed by gender using repeated ANOVA, both for ceiling and wall cooling systems, but no significant differences were observed. The answers given by the subjects were compared with the calculated PMV values using the repeated ANOVA method. The results are presented in Tables 2-5.

For the measurements related to ceiling cooling, the air velocity was not acceptable in the first half hour for $75-95 \%$ of subjects, who wanted a higher air velocity. After switching the ventilation and cooling system on, after 15 minutes of operation, $45 \%$ of subjects declared that the air velocity was acceptable. The share of positive answers increased further and, after one hour of operation, reached $85-95 \%$. For question
5 (related to indoor air quality), the same trend was observed. Even though the ventilation system and cooling system were switched off for the last 30 minutes of measurements, $79.2-87.5 \%$ of the occupants accepted the air velocity and the indoor air quality. For the question related to draughts, the subjects answer was "Not" in a high percent during the whole measurement period (the lowest share of negative answers was $75 \%$, the highest was $100 \%$ ). For question 4 (related to the surface temperature of the closing elements), the share of dissatisfied persons was high only during the first half hour of the measurements (approximately 62.5\% would like to decrease the surface temperatures). After switching the ventilation and the cooling system on, the share of dissatisfied subjects decreased every

Table 3. Significance analysis between the calculated PMV and the subjective thermal comfort of occupants (wall cooling, women)

\begin{tabular}{lccccccl}
\hline & Mean Diff & SEM & Alpha & Sig & LCL & UCL & \multicolumn{1}{c}{ Overall ANOVA } \\
\hline $0: 00$ & -0.009 & 0.149 & 0.05 & 0 & -0.318 & 0.299 & No significant difference \\
$0: 15$ & 0.301 & 0.165 & 0.05 & 0 & -0.042 & 0.644 & Significant difference \\
$0: 30$ & 0.653 & 0.195 & 0.05 & 1 & 0.249 & 1.058 & Significant difference \\
$0: 45$ & 0.676 & 0.179 & 0.05 & 1 & 0.306 & 1.046 & Significant difference \\
$1: 00$ & 0.802 & 0.178 & 0.05 & 1 & 0.433 & 1.170 & Significant difference \\
$1: 15$ & 0.790 & 0.191 & 0.05 & 1 & 0.395 & 1.185 & Significant difference \\
$1: 30$ & 0.866 & 0.239 & 0.05 & 1 & 0.369 & 1.362 & Significant difference \\
$1: 45$ & 0.949 & 0.170 & 0.05 & 1 & 0.596 & 1.302 & Significant difference \\
$2: 00$ & 1.032 & 0.197 & 0.05 & 1 & 0.623 & 1.441 & Significant difference \\
$2: 15$ & 1.075 & 0.184 & 0.05 & 1 & 0.693 & 1.456 & Significant difference \\
$2: 30$ & 1.124 & 0.187 & 0.05 & 1 & 0.737 & 1.512 & Significant difference \\
$2: 45$ & 1.229 & 0.186 & 0.05 & 1 & 0.843 & 1.615 & Significant difference \\
$3: 00$ & 1.415 & 0.191 & 0.05 & 1 & 1.018 & 1.812 & Significant difference \\
\hline
\end{tabular}

Table 4. Significance analysis between the calculated PMV and the subjective thermal comfort of occupants (ceiling cooling, men)

\begin{tabular}{lcccccll}
\hline & Mean Diff & SEM & Alpha & Sig & LCL & UCL & Overall ANOVA \\
\hline $0: 00$ & 0.293 & 0.198 & 0.05 & 0 & -0.118 & 0.703 & No significant difference \\
$0: 15$ & 0.318 & 0.211 & 0.05 & 0 & -0.120 & 0.755 & No significant difference \\
$0: 30$ & 0.442 & 0.274 & 0.05 & 0 & -0.126 & 1.010 & No significant difference \\
$0: 45$ & 0.551 & 0.228 & 0.05 & 1 & 0.078 & 1.024 & Significant difference \\
$1: 00$ & 0.587 & 0.224 & 0.05 & 1 & 0.121 & 1.052 & Significant difference \\
$1: 15$ & 0.795 & 0.218 & 0.05 & 1 & 0.343 & 1.247 & Significant difference \\
$1: 30$ & 1.080 & 0.213 & 0.05 & 1 & 0.638 & 1.522 & Significant difference \\
$1: 45$ & 1.236 & 0.198 & 0.05 & 1 & 0.825 & 1.647 & Significant difference \\
$2: 00$ & 1.495 & 0.200 & 0.05 & 1 & 1.081 & 1.910 & Significant difference \\
$2: 15$ & 1.594 & 0.233 & 0.05 & 1 & 1.110 & 2.078 & Significant difference \\
$2: 30$ & 1.572 & 0.243 & 0.05 & 1 & 1.069 & 2.076 & Significant difference \\
$2: 45$ & 1.688 & 0.237 & 0.05 & 1 & 1.196 & 2.180 & Significant difference \\
$3: 00$ & 1.519 & 0.236 & 0.05 & 1 & 1.029 & 2.009 & Significant difference \\
\hline & & & & & & &
\end{tabular}


Table 5. Significance analysis between the calculated PMV and the subjective thermal comfort of occupants (ceiling cooling, women)

\begin{tabular}{lcccccll}
\hline & Mean Diff & SEM & Alpha & Sig & LCL & UCL & Overall ANOVA \\
\hline $0: 00$ & 0.172 & 0.146 & 0.05 & 0 & -0.130 & 0.474 & No significant difference \\
$0: 15$ & 0.374 & 0.142 & 0.05 & 1 & 0.079 & 0.669 & Significant difference \\
$0: 30$ & 0.699 & 0.165 & 0.05 & 1 & 0.357 & 1.040 & Significant difference \\
$0: 45$ & 0.660 & 0.178 & 0.05 & 1 & 0.292 & 1.028 & Significant difference \\
$1: 00$ & 0.849 & 0.176 & 0.05 & 1 & 0.485 & 1.214 & Significant difference \\
$1: 15$ & 1.095 & 0.195 & 0.05 & 1 & 0.690 & 1.499 & Significant difference \\
$1: 30$ & 1.040 & 0.149 & 0.05 & 1 & 0.731 & 1.348 & Significant difference \\
$1: 45$ & 1.337 & 0.192 & 0.05 & 1 & 0.938 & 1.735 & Significant difference \\
$2: 00$ & 1.236 & 0.200 & 0.05 & 1 & 0.821 & 1.651 & Significant difference \\
$2: 15$ & 1.575 & 0.219 & 0.05 & 1 & 1.121 & 2.029 & Significant difference \\
$2: 30$ & 1.519 & 0.238 & 0.05 & 1 & 1.025 & 2.013 & Significant difference \\
$2: 45$ & 1.447 & 0.229 & 0.05 & 1 & 0.972 & 1.923 & Significant difference \\
$3: 00$ & 1.148 & 0.225 & 0.05 & 1 & 0.682 & 1.614 & Significant difference \\
\hline & & & & & & &
\end{tabular}

15 minutes and reached $12.5 \%$ after one hour of operation.

For wall cooling, the air velocity was not acceptable in the first 30 minutes for $62.5 \%$ of the subjects (they wanted to increase the air velocity). After switching the ventilation and cooling system on, the percent of dissatisfied persons decreased. Nevertheless, the highest share of satisfied persons was $87.5 \%$, and after switching the ventilation and cooling system off, the subjects reacted promptly. The share of satisfied persons decreased to $70 \%$ within 30 minutes. The trend was similar in the case of the last question (related to indoor air quality). At the start of the measurements, the share of satisfied persons was $20.8 \%$. After switching the ventilation and cooling system on, this percent increased and reached $91.7 \%$ before switching the systems off. At 30 minutes, the share of persons satisfied with the indoor air quality decreased to $79.2 \%$. The highest share of subjects who felt draughts was $20.8 \%$. The share of subjects who did not feel draughts reached $100 \%$ for longer periods compared with ceiling cooling. At the beginning, approximately $50 \%$ of subjects were content with the surface temperature. After switching the ventilation and wall cooling system on, the share of satisfied persons increased to $87.5 \%$ (the highest value). After switching the wall cooling system and the ventilation system off, the occupant's reaction was prompt. The share of satisfied persons decreased to $75 \%$.

\section{Conclusion}

The aim of our research was to analyse ceiling cooling and wall cooling systems from a thermal comfort point of view. The measurements were performed in the Laboratory of Indoor Environment Quality, Fac- ulty of Engineering, University of Debrecen. Because of the use of the same cooling surface and same supply and return temperatures, the obtained subjective thermal comfort was similar. No significant differences between the answers were found. However, when testing the environment with a high heat load, the subjective answers were lower than the calculated PMV values. Significant differences were found between the subjective answers and the calculated PMV values. Furthermore, after decoupling the ventilation and cooling systems, the share of satisfied persons decreased by a small amount in the case of ceiling cooling, whereas in the case of the wall cooling system, the percentage of dissatisfied occupants increased significantly. This phenomena needs to be tested further in detail in the future.

\section{Acknowledgements}

The work is supported by the EFOP-3.6.1-16-201600022 project. The project is co-financed by the European Union and the European Social Fund.

\section{References}

[1] Luterbacher J., Dietrich D., Xoplaki E., Grosjean M., Wanner H. (2004), European seasonal and annual temperature variability, trends, and extremes since 1500 . Science, 303, 1499-1503.

[2] Schär Ch., Vidale P. L., Lüthi D., Frei Ch., Häberli Ch., Liniger M. A., Appenzeller Ch. (2004), The role of increasing temperature variability in European summer heatwaves. Nature, 427, 332-336.

[3] Fischer E. M., Seneviratne S. I., Vidale P. L., Lüthi D., Schär C. (2007), Soil moisture-atmosphere interactions during the 2003 European summer heat wave. J. Climate, 20, 5081-5099. 
[4] Zampieri M., D’Andrea, F., Vautard R., Ciais Ph., de Noblet-Ducoudré N., Yiou P. (2009), Hot European summers and the role of soil moisture in the propagation of Mediterranean drought. J. Climate, 22, 4747-4758.

[5] Kysely J. (2010), Recent severe heat waves in central Europe: How to view them in a long-term prospect? Int. J. Climatol., 30, 89-109.

[6] Founda D., Giannakopoulos C. (2009), The exceptionally hot summer of 2007 in Athens, Greece - A typical summer in the future climate? Global and Planetary Change, 67, 227-236.

[7] Grumm R. H. (2011), The Central European and Russian heat event of July-August 2010. Bull. Amer. Meteor. Soc., 92, 1285-1296.

[8] Barriopedro D., Fischer E. M., Luterbacher J., Trigo R. M., García-Herrera R. (2011), The hot summer of 2010: Redrawing the temperature record map of Europe. Science, 332, 220-224.

[9] Pantavou K., Theoharatos G., Mavrakis A., Santamouris M. (2011), Evaluating thermal comfort conditions and health responses during an extremely hot summer in Athens. Building and Environment, 46, 339-344.

[10] Nikolopoulou M., Lykoudis S. (2006), Thermal comfort in outdoor urban spaces: Analysis across different European countries. Building and Environment, 41, 1455-1470.

[11] Theoharatos G., Pantavou K., Mavrakis A., Spanou A., Katavoutas G., Efstathiou P., Mpekas P., Asimakopoulos D. (2010), Heat waves observed in 2007 in Athens, Greece: Synoptic conditions, bioclimatological assessment, air quality levels and health effects. Environmental Research, 110, 152-161.

[12] Stetiu C. (1999), Energy and peak power savings potential of radiant cooling systems in US commercial buildings. Energy and Buildings, 30, 127-138.
[13] Imanari T., Omori T., Bogaki K. (1999), Thermal comfort and energy consumption of the radiant ceiling panel system. Comparison with the conventional all-air system. Energy and Buildings, 30, 167-175.

[14] Kitagawa K., Komoda N., Hayano H., Tanabe Sh. (1999), Effect of humidity and small air movement on thermal comfort under a radiant cooling ceiling by subjective experiments. Energy and Buildings, 30, 185-193.

[15] Miriel J., Serres L., Trombe A. (2002), Radiant ceiling panel heating-cooling systems: experimental and simulated study of the performances, thermal comfort and energy consumptions. Applied Thermal Engineering, 22, 1861-1873.

[16] Tian Zh., Love J. A. (2008), A field study of occupant thermal comfort and thermal environments with radiant slab cooling. Building and Environment, 43, 1658-1670.

[17] Memon R. A., Chirarattananon S., Vangtook P. (2008), Thermal comfort assessment and application of radiant cooling: A case study. Building and Environment, 43, 1185-1196.

[18] Oxizidis S., Papadopoulos A. M. (2013), Performance of radiant cooling surfaces with respect to energy consumption and thermal comfort. Energy and Buildings, 57, 199209.

[19] ISO 7730-2005: Ergonomics of the thermal environment - Analytical determination and interpretation of thermal comfort using calculation of the PMV and PPD indices and local thermal comfort criteria.

[20] ISO 7933-2004: Ergonomics of the thermal environment Analytical determination and interpretation of heat stress using calculation of the predicted heat strain. 